ARTIGO ORIGINAL

\title{
Variabilidade genética em progênies de Campomanesia xanthocarpa Mart. ex O. Berg em viveiro
}

\author{
Genetic variability in nusery-grown progenies of Campomanesia \\ xanthocarpa Mart. ex O. Berg
}

\author{
Mariá Bach Kampa ${ }^{1}$ (D), Isabel Homczinski ${ }^{1}$ (D), Rafael Henrique Roque ${ }^{2}$ (D), Afonso Figueiredo Filho ${ }^{1}$ (D), \\ Fabiana Schmidt Bandeira Peres ${ }^{1}$ (D), Evandro Vagner Tambarussi ${ }^{1}$ (D) \\ ${ }^{1}$ Universidade Estadual do Centro-Oeste - Unicentro, Irati, PR, Brasil \\ 2Escola Superior de Agricultura "Luiz de Queiroz" - ESALQ, Universidade de São Paulo - USP, Piracicaba, SP, Brasil
}

Como citar: Kampa, M. B., Homczinski, l., Roque, R. H., Figueiredo Filho, A., Peres, F. S. B., \& Tambarussi, E. V. (2020). Variabilidade genética em progênies de Campomanesia xanthocarpa Mart. ex O. Berg em viveiro. Scientia Forestalis, 48(125), e2935. https://doi.org/10.18671/scifor.v48n125.10

\begin{abstract}
Resumo
O presente estudo baseia-se na necessidade de investigar a variabilidade genética de Campomanesia xanthocarpa $\mathrm{O}$. Berg. visando um melhor conhecimento sobre seu desenvolvimento e fornecendo informações para sua conservação, melhoramento genético e manejo sustentável. Esta pesquisa teve por objetivo acessar a variabilidade genética entre e dentro de progênies de $C$. xanthocarpa e realizar a implantação do primeiro programa de melhoramento genético da espécie. Para tanto, realizou-se um teste de progênies em viveiro sob delineamento em blocos ao acaso, com nove progênies maternas, três repetições e seis plantas por repetição, avaliando o diâmetro de coleto ( $\mathrm{DC}, \mathrm{mm})$, altura ( $\mathrm{ALT}, \mathrm{mm})$, número de folhas (NF) e de brotações (Bro) aos 11, 13 e 15 meses de idade. A média da ALT e DC ao final do experimento foi de $172,57 \mathrm{~mm}$ e $5,75 \mathrm{~mm}$, respectivamente. A herdabilidade individual $\left(\hat{h}_{a}^{2}\right)$ apresentou valores variando de 0,39 (DC) a 0,81 (NF). O coeficiente de variação genética individual ( $C \hat{V}_{g i} \%$ ) e o coeficiente de variação entre progênies ( $C \hat{V}_{g p} \%$ ) variaram de 11,42\% (ALT) a 47,20\% (NF) e de 8,12\% (DC) a $23,60 \%$ (NF), respectivamente. O coeficiente de variação relativa $(\hat{b})$ variou de baixa a moderada magnitude (0,23 a 0,49, para DC e NF, respectivamente). A acurácia preditiva foi considerada alta para todos os caracteres avaliados $\left(\hat{r}_{a a} \geq 0,70\right)$. Os resultados deste estudo permitem concluir que existe variabilidade genética entre e dentro de progênies, demonstrando o alto potencial desta espécie para programas de melhoramento e conservação.
\end{abstract}

Palavras-chave: Genética quantitativa; Espécie nativa; Frutífera; Teste de progênies em viveiro.

\begin{abstract}
The present study investigates the variability of Campomanesia xanthocarpa O. Berg. in order to better understand its development and inform conservation, genetic improvement and sustainable management strategies. The aim of the analysis was to assess genetic variability among and within progenies of $C$. xanthocarpa to develop the first genetic improvement program for this species. A progeny trial was conducted in a nursery using a randomized complete block design, consisting of nine treatments (progenies), three replicates and six plants per replicate. The following traits were evaluated at 11, 13 and 15 months of age: root-collar diameter (RCD, $\mathrm{mm}$ ) seedling height $(\mathrm{SH}, \mathrm{mm})$, number of leaves $(\mathrm{NL})$ and number of shoots (NS). At the end of the experiment, the average for SH and RCD were $172.57 \mathrm{~mm}$ and $5.75 \mathrm{~mm}$, respectively. We found high magnitude values for mean heritability $\left(\hat{h}_{m}^{2}\right)$ of the evaluated traits,
\end{abstract}

Fonte de financiamento: Nenhuma.

Conflito de interesse: Nada a declarar.

Autor correspondente: tambarussi@gmail.com

Recebido: 15 junho 2018

Aceito: 3 junho 2019

Editor: Francides Gomes da Silva Júnior.

cc) (i) Este é um artigo publicado em acesso aberto (Open Access) sob a licença Creative Commons Attribution, que permite uso, distribuição e reprodução em qualquer meio, sem restrições desde que o trabalho original seja corretamente citado. 
ranging from $0.39(\mathrm{RCD})$ to $0.81(\mathrm{NL})$. The coefficient of individual genetic variation $\left(C \hat{V}_{g i} \%\right)$ ranged from $11.42 \%(\mathrm{SH})$ to $47.20 \%(\mathrm{NL})$ and the coefficient of variation among progenies ( $C \hat{V}_{g p} \%$ ) ranged from $8.12 \%$ (RCD) to $23.60 \%(\mathrm{NL})$, both of which are considered high. The relative coefficient of variation $(\hat{b})$ was moderate for the evaluated variables and ranged from 0.23 to 0.49 for RCD and NL, and the selective accuracy was considered high for all evaluated traits $\left(\hat{r}_{a a} \geq 0.70\right)$. Our results confirm the presence of genetic variability among and within progenies of $C$. xanthocarpa, highlighting the significant potential of this species for genetic improvement and conservation programs.

Keywords: Quantitative genetics; Native species; Fruit trees; Nursery-grown progeny trials.

\section{INTRODUÇÃO}

A espécie Campomanesia xanthocarpa O. Berg. é conhecida popularmente como guabiroba, guabirobeira e guabirobeira-do-mato. Pertence à família Myrtaceae (Lorenzi, 2009) que é considerada uma das famílias mais importantes dos neotrópicos (Sarmento et al., 2012). É originária da América do Sul; no Brasil ocorre desde o estado de Minas Gerais até o Rio Grande do Sul (Sarmento et al., 2012; Reflora, 2016), sendo relatada na literatura a presença dessa espécie no Paraguai e no nordeste da Argentina (Sarmento et al., 2012).

Essa espécie ocorre na Floresta Estacional Semidecidual, Floresta Ombrófila Mista Aluvial e Floresta Ombrófila Mista Montana (Reflora, 2016), sendo que sua frequência pode variar conforme a sucessão ecológica (Homczinski, 2017). Ocorre especialmente nos solos úmidos, nos capões e em áreas mais abertas da floresta secundária. Considerada rústica e resistente a condições adversas (poluição e frio) (Gogosz, 2008), em terrenos acidentados, com encharcamento periódico e de baixa fertilidade natural, sendo ideal para formação de floresta de várzea e recuperação de áreas degradadas (Carvalho \& Nakagawa, 2000; Lorenzi, 2009).

É considerada uma espécie heliófila, seletiva higrófita (Lorenzi, 2009; Backes \& Irgang, 2002) e esciófita (Carvalho, 2006) de médio porte, podendo atingir até $25 \mathrm{~m}$ de altura (Backes \& Irgang, 2002; Homczinski et al., 2017) com fuste levemente tortuoso (Homczinski, 2017), com casca pardo-acinzentada (Backes \& Irgang, 2002; Carvalho, 2006) suberosa e descamante (Lorenzi, 2009) que se solta em tiras longitudinais (Backes \& Irgang, 2002) e o diâmetro à altura do peito (DAP) pode atingir de 50 a 60 cm (Schaaf et al., 2009; Figueiredo Filho et al., 2013; Homczinski et al., 2017). A floração ocorre entre os meses de setembro e outubro e a frutificação ocorre entre os meses de outubro e dezembro (Backes \& Irgang, 2002; Homczinski, 2017).

A madeira é pesada, dura e resistente, com boa durabilidade natural, podendo ser utilizada para confecção de tabuados em geral, instrumentos musicais e cabos de ferramentas, além de lenha e carvão para produção de energia (Backes \& Irgang, 2002; Lorenzi, 2009). Relata-se, também, a utilização da espécie em projetos paisagísticos (Backes \& Irgang, 2002; Carvalho, 2006; Lorenzi, 2009) e na ornamentação de praças e avenidas (Carvalho, 2006).

A espécie é considerada melífera (Lorenzi, 2009), medicinal (Biavatti et al., 2004; Klafke et al., 2010; Vinagre et al., 2010) e frutífera (Lorenzi, 2009). Os frutos são muito apreciados por pássaros e peixes, sendo indicada para o plantio em áreas degradadas, com função de preservação permanente (Backes \& Irgang, 2002). A espécie já foi utilizada como bioindicadora na recuperação de áreas contaminadas por petróleo, mostrando-se tolerante a este poluente, entretanto, a contaminação afetou a morfologia e a anatomia das plântulas, principalmente as raízes (Gogosz, 2008).

Os frutos possuem um alto valor nutricional, contendo vitamina $C$, teores substanciais de flavonoides e compostos fenólicos totais. Além dos frutos possuírem um baixo teor calórico, apresentam também altos teores de minerais, como ferro, cálcio, fósforo e zinco, se comparados a frutos que são conhecidos e consumidos com mais frequência, como a maçã e a banana (Vallilo et al., 2008; Santos et al., 2009). O fruto pode ser utilizado na produção de sucos, geleias, sorvetes, licores, ou mesmo in natura (Santos et al., 2009), tendo grande potencial na fruticultura do país, apresentando uma boa aceitação dos produtos pelo público avaliado (Freitas et al., 2008).

Além de estudos sobre a germinação, crescimento das mudas, tratamentos nutricionais e formas de plantio (Gogosz et al., 2010; Herzog et al., 2012; Dalanhol et al., 2017), C. xanthocarpa também foi pesquisada quanto sua biometria e produtividade frutífera em 
área nativa, o que ressalta a viabilidade da sua produção e manejo em propriedades rurais (Homczinski et al., 2017).

Apesar da sua importância ecológica e do potencial para comercialização de seus frutos, estudos acerca da variabilidade genética da espécie são inexistentes, sendo necessária sua análise com o intuito de fornecer informações importantes para sua conservação, melhoramento genético e manejo sustentável. Entretanto, para estudar a variabilidade genética de uma espécie, deve-se, primeiramente, entender que esta variabilidade se encontra distribuída entre e dentro de populações e estruturada a partir dos resultados de processos evolutivos, como migração, mutação, seleção e deriva genética (Hartl, 2008).

Uma forma de se obter a grandeza da variabilidade genética de uma população natural é entender o controle genético de caracteres adaptativos e de importância silvicultural. Seu uso é muito importante para a avaliação da performance dos indivíduos selecionados, na estimativa de parâmetros genéticos para a seleção de novos indivíduos superiores e como fonte de produção de sementes por meio da sua transformação em pomar de sementes por mudas (Kageyama \& Vencovsky, 1983; Aguiar et al., 2010), que consiste na plantação de mudas de árvores selecionadas geneticamente, isoladas para reduzir a polinização de fontes externas geneticamente inferiores (Aguiar et al., 2010).

O teste de progênies possibilita definir a proporção da variação genética adaptativa mediante análises de caracteres quantitativos que podem responder a alterações ambientais ou mesmo ser analisada em programas de melhoramento genético (Freitas et al., 2007). Os caracteres quantitativos são aqueles controlados por vários genes e possuem forte influência do ambiente, podendo apresentar variações contínuas e, às vezes, descontínuas (Cruz, 2005).

As análises estatísticas de caracteres quantitativos determinam o melhor e mais adequado método de seleção para se explorar a variabilidade genética presente em uma população, além de compreender sua estrutura genética (Cruz, 2005). Dentre os parâmetros genéticos avaliados, os de maior importância ao melhorista e que são mais usados para estudos em testes de procedências e progênies são as variâncias genéticas, os coeficientes de variação, a herdabilidade no sentido amplo e restrito e o ganho genético (Vencovsky \& Barriga, 1992; Borém \& Miranda, 2009).

Dessa forma, o objetivo da presente pesquisa foi acessar a variabilidade genética entre e dentro de progênies de C. xanthocarpa e realizar a implantação do primeiro programa de melhoramento genético da espécie, tendo como objetivos específicos: i) Estimar parâmetros genéticos visando obter subsídios para programas de melhoramento e conservação genética da espécie; ii) Quantificar a variação genética existente entre e dentro de progênies por meio de variáveis quantitativas; iii) Verificar a superioridade das árvores matrizes em relação às suas progênies. Neste sentido a hipótese testada considerou que a população amostrada apresenta variabilidade genética significativa para subsidiar programas de melhoramento e conservação genética da espécie.

\section{MATERIAL E MÉTODOS}

\section{Área de estudo e instalação do experimento}

A coleta das sementes de C. xanthocarpa foi realizada na Floresta Nacional de Irati (FLONA de Irati), localizada entre os municípios de Fernandes Pinheiro e Teixeira Soares, estado do Paraná, estando sob as coordenadas geográficas de 50³3'44,889"W de latitude e $25^{\circ} 20^{\prime} 24,818^{\prime \prime}$ S de longitude (Pinheiro, 2013). Para a coleta das sementes foram selecionadas nove árvores matrizes com distância mínima de 20 m entre elas, com o intuito de evitar a coleta de árvores aparentadas. As árvores matrizes foram submetidas a seleção massal, de forma que as sementes foram coletadas de indivíduos fenotipicamente superiores aos demais, em relação às variáveis altura, diâmetro à altura do peito (DAP) e diâmetro e altura da copa.

A semeadura foi realizada no dia 21 de novembro de 2016 em tubetes de polipropileno com volume de $120 \mathrm{~cm}^{3}$ contendo substrato comercial de casca de pinus e $100 \mathrm{~g}$ de Osmocote ${ }^{\circledR}$ 14-14-14 
Classic (3 a 4 meses) (fertilizante de liberação controlada), para cada $25 \mathrm{~kg}$ de substrato, permanecendo na casa de vegetação da Universidade Estadual do Centro-Oeste, UNICENTRO, Campus de Irati, estado do Paraná, entre as coordenadas geográficas $50^{\circ} 38^{\prime}$ e $50^{\circ} 40^{\prime}$ de longitude oeste e $25^{\circ} 28^{\prime}$ e $25^{\circ} 27^{\prime}$ de latitude sul, até os três meses de idade.

Após esse período as mudas foram rustificadas em viveiro e aos seis meses foram transplantadas para embalagens definitivas (sacos plásticos de polipropileno) de $15 \mathrm{~cm}$ de largura, $25 \mathrm{~cm}$ altura e 0,15 micragem, em substrato contendo solo (60\%), areia (40\%) e $100 \mathrm{~g}$ de fertilizante Osmocote ${ }^{\circledR}$ para cada 18 litros, permanecendo em viveiro até os 15 meses e, posteriormente, foram levadas para implantação em campo.

Em 29 de setembro de 2017, o experimento foi instalado no viveiro sob delineamento em blocos ao acaso (DBC), com nove tratamentos (progênies) com três repetições e seis mudas por repetição, totalizando 162 mudas.

Após um mês, realizou-se a fertilização com NPK 04-14-08 (nitrogênio, fósforo e potássio), sendo aplicados $50 \mathrm{ml}$ de fertilizante por embalagem individual a cada duas semanas. Aos 60 dias após a implantação do experimento foi realizada a primeira avaliação e, posteriormente, a cada dois meses, totalizando três observações, aos 11, 13 e 15 meses de idade.

As progênies foram avaliadas quanto as seguintes variáveis: altura total (ALT, mm), diâmetro de coleto (DC, mm), número de folhas (NF) e número de brotações (Bro). Na terceira avaliação (15 meses), realizou-se apenas a coleta dos dados referentes ao diâmetro do coleto e à altura, sendo que em virtude dos tratos culturais (poda nas folhas) a contagem do NF e Bro não foi realizada.

\section{Análise de dados}

A análise da variância (ANOVA) para os caracteres quantitativos de plantas individuais foi realizada considerando os efeitos de bloco e progênies como aleatórios e os efeitos do local (viveiro) como fixos, utilizando o seguinte modelo estatístico: $Y_{i j k}=\mu+b_{j}+p_{i}+\varepsilon_{i j}+\delta_{i j k}$. Em que, $Y_{i j k}$ é o valor fenotípico do $k$-ésimo indivíduo do j-ésimo bloco da $i$-ésima progênie; $\mu$ é a média geral da caráter em análise; $b_{j}$ é o efeito do j-ésimo bloco; $p_{i}$ é o efeito da $i$-ésima progênie; $\varepsilon_{i j}$ é o efeito da interação entre a $i$-ésima progênie e o j-ésimo bloco (erro entre progênies); $\delta_{i j k}$ é o efeito do erro dentro de progênies.

A significância dos efeitos foi constatada por meio do teste $F$, utilizando o pacote estatístico "MASS" no software estatístico R, versão "3.4.2" (Venables \& Ripley, 2002). Utilizando os seguintes componentes: variância genética entre progênies $\left(\sigma_{g p}^{2}\right)$, variância ambiental $\left(\sigma_{e}^{2}\right)$ e variância fenotípica dentro de progênies ( $\left.\sigma_{a d}^{2}\right)$.

Os parâmetros genéticos foram estimados a partir dos componentes de variância da ANOVA. As herdabilidades foram estimadas em nível individual de plantas no sentido restrito $\left(\hat{h}_{i}^{2}=\frac{4 \hat{\sigma}_{g p}^{2}}{\hat{\sigma}_{g p}^{2}+\hat{\sigma}_{e}^{2}+\hat{\sigma}_{a d}^{2}}\right)$, herdabilidade dentro de progênies $\left(\hat{h}_{a d}^{2}=\frac{3 \hat{\sigma}_{g p}^{2}}{\hat{\sigma}_{a d}^{2}}\right)$ e ao nível de média de famílias $\left(\hat{h}_{m}^{2}=\frac{\hat{\sigma}_{g p}^{2}}{\hat{\sigma}_{g p}^{2}+\frac{\hat{\sigma}_{e}^{2}}{b}+\frac{\hat{\sigma}_{a d}^{2}}{n b}}\right)$, conforme Vencovsky \& Barriga (1992). Em que: $\hat{\sigma}_{g p}^{2}$ : variância genética entre progênies; $\hat{\sigma}_{e}^{2}$ : variância ambiental; $\hat{\sigma}_{a d}^{2}$ : variância fenotípica dentro de progênies; $n$ : número de indivíduos/parcela; $b$ : número repetições/blocos.

Os coeficientes de variação estimados foram: coeficiente de variação genética aditiva individual $\left(C \hat{V}_{g i}(\%)=\frac{\sqrt{\hat{\sigma}_{a}^{2}}}{\bar{m}} \cdot 100\right)$, coeficiente de variação genética entre progênies $\left(C \hat{V}_{g p}(\%)=\frac{\sqrt{\hat{\sigma}_{g p}^{2}}}{\bar{m}} \cdot 100\right)$, coeficiente de variação ambiental $\left(C \hat{V}_{e}(\%)=\frac{\sqrt{Q M_{\text {residuos }}}}{\bar{m}} .100\right)$, coeficiente de variação relativo $\left(\hat{b}=\frac{C \hat{V}_{g p}}{C \hat{V}_{e}}\right)$, conforme Vencovsky \& Barriga (1992). Em que: $\hat{\sigma}_{a}^{2}$ : variância genética aditiva; $\hat{\sigma}_{g p}^{2}$ : variância genética entre progênies; $\bar{m}$ : média das progênies; $Q M_{\text {residuos }}$ : Quadrado médio do resíduo entre progênies. 
Para amparar a seleção das melhores progênies foi estimada a acurácia na seleção de progênies $\left(\hat{r}_{a a}=\sqrt{\hat{h}_{m}^{2}}\right)$, conforme Vencovsky \& Barriga (1992).

\section{RESULTADOS E DISCUSSÃO}

As análises de variância demonstraram valores significativos para todos os caracteres avaliadas pelo teste de $F$ ( $p$-valor $<0,01)$, indicando que houve diferença significativa no desempenho das progênies para esses caracteres, bem como possibilidade de seleção de genótipos superiores entre e dentro de progênies de C. xanthocarpa a serem utilizadas em programas de melhoramento e conservação genética (Tabela 1).

Tabela 1: Quadrados médios obtidos para cada um dos caracteres nos efeitos avaliados para C. xanthocarpa em experimento de delineamento em blocos ao acaso (DBC) avaliadas aos 11, 13 e 15 meses em viveiro florestal na Universidade Estadual do Centro Oeste, Campus de Irati, Paraná.

\begin{tabular}{|c|c|c|c|c|c|c|c|c|c|c|c|}
\hline \multirow{3}{*}{ FV } & \multicolumn{11}{|c|}{ Quadrados Médios } \\
\hline & \multirow[t]{2}{*}{ GL } & \multicolumn{3}{|c|}{ Diâmetro do coleto (mm) } & \multicolumn{2}{|c|}{ Altura (mm) } & \multicolumn{3}{|c|}{ Número de folhas } & \multicolumn{2}{|c|}{$\begin{array}{l}\text { Número de } \\
\text { brotações }\end{array}$} \\
\hline & & 11 meses & 13 meses & 15 meses & 11 meses & 13 meses & 15 meses & 11 meses & 13 meses & 11 meses & 13 meses \\
\hline Blocos & 2 & $4,49 * *$ & $11,32^{\star \star}$ & $15,04 * *$ & $4.622,40 * \star$ & $3.955,90 * *$ & $12.211,40 * \star$ & $166,24^{\star \star}$ & $275,26 * \star$ & $243,43^{* *}$ & $235,37 * \star$ \\
\hline Progênie & 8 & $6,41 * *$ & $21,18^{\star *}$ & $24,45^{\star *}$ & $4.384,40 * *$ & $7.507,00 * \star$ & $12.915,10^{\star \star}$ & $616,74 * *$ & $804,69 * *$ & $632,76^{* *}$ & $617,08^{* *}$ \\
\hline Erro ENTRE & 16 & 3,65 & 9,67 & 12,27 & 954,40 & $1.970,90$ & $4.113,80$ & 116,25 & 159,20 & 156,20 & 142,89 \\
\hline Erro DENTRO & 120 & 1,40 & 3,64 & 4,44 & 828,40 & $1.880,90$ & $2.525,10$ & 110,95 & 136,83 & 122,51 & 131,29 \\
\hline
\end{tabular}

FV: fonte de variação; $G L$ : graus de liberdade; **: significativo pelo teste $F(p<0,01)$.

Foram realizadas as estimativas das variâncias genéticas, bem como das herdabilidades, coeficientes de variação genética e experimental e as médias fenotípicas das progênies de C. xanthocarpa para os caracteres: diâmetro de coleto (DC, $\mathrm{mm}$ ), altura (ALT, mm), número de folhas (NF) e número de brotações (Bro) em diferentes idades (11, 13 e 15 meses) e os dados destes parâmetros estão descritos na Tabela 2.

Os valores médios dos caracteres avaliados de $C$. xanthocarpa para ALT e DC nas três medições (11, 13 e 15 meses) do experimento foram de 120,79 mm; 150,18 mm e 172,57 mm e 3,16 mm; 5,02 mm e 5,75 mm, respectivamente, enquanto que os caracteres NF e Bro nas duas medições (11 e 13 meses) apresentaram média fenotípica de 22 e 28 , e 29 e 35 , respectivamente.

Em experimento com Campomanesia pubescens (DC) O. Berg, Bardiviesso et al. (2011) foram observados valores de altura de $50 \mathrm{~mm}$ para mudas com três meses de idade em substrato com solo e esterco bovino, na proporção 3:1. No entanto, Correia et al. (2005) constataram altura de $256,00 \mathrm{~mm}$ para mudas de Psidium guajava L. cultivadas em substrato contendo $50 \%$ de vermicomposto e $50 \%$ de casca de arroz carbonizada. Comparados com o presente estudo, os resultados obtidos nesses trabalhos evidenciam as diferenças fenotípicas no crescimento de espécies da família Myrtaceae, tendo ainda como influência a idade de avaliação e o substrato utilizado para a produção das mudas.

De acordo com Dalanhol et al. (2017), em experimento avaliando o efeito da inoculação de fungos micorrízicos arbusculares, da adubação e da composição do substrato sobre o crescimento de mudas de $C$. xanthocarpa, foram verificadas alturas variando entre $50 \mathrm{~mm}$ (sem adubação) e $250 \mathrm{~mm}$ (com adubação), e DC variando entre 1,0 $\mathrm{mm}$ (sem adubação) e 3,5 mm (com adubação), aos seis meses de idade. Esses resultados diferem dos obtidos na presente pesquisa, podendo este fato ser atribuído a diferenças de adubação e a fatores ambientais. Há de se destacar que Dalanhol et al. (2017), além de testar a inoculação de micorrizas, comparou a utilização de diferentes substratos, concluindo que o substrato à base de vermicomposto e casca de arroz pode substituir o substrato comercial à base de casca de pinus, no qual verificou-se crescimento reduzido das mudas para variáveis biométricas. 
Tabela 2: Estimativa de parâmetros genéticos para os caracteres diâmetro do coleto $(\mathrm{mm})$, altura ( $\mathrm{mm})$, número de folha e número de brotações de progênies de $C$. xanthocarpa, avaliadas aos 11,13 e 15 meses em viveiro florestal na Universidade Estadual do Centro Oeste, Campus de Irati, Paraná.

\begin{tabular}{|c|c|c|c|c|c|c|c|c|c|c|}
\hline \multirow{2}{*}{$\begin{array}{l}\text { Parâmetro } \\
\text { s } \\
\text { Genéticos }\end{array}$} & \multicolumn{3}{|c|}{$\begin{array}{l}\text { Diâmetro do coleto } \\
\text { (mm) }\end{array}$} & \multicolumn{3}{|c|}{ Altura (mm) } & \multicolumn{2}{|c|}{$\begin{array}{l}\text { Número de } \\
\text { folhas }\end{array}$} & \multicolumn{2}{|c|}{$\begin{array}{l}\text { Número de } \\
\text { brotações }\end{array}$} \\
\hline & $\begin{array}{c}11 \\
\text { meses }\end{array}$ & $\begin{array}{c}13 \\
\text { meses }\end{array}$ & $\begin{array}{c}15 \\
\text { meses }\end{array}$ & $\begin{array}{c}11 \\
\text { meses }\end{array}$ & $\begin{array}{c}13 \\
\text { meses }\end{array}$ & $\begin{array}{c}15 \\
\text { meses }\end{array}$ & $\begin{array}{c}11 \\
\text { meses }\end{array}$ & $\begin{array}{c}13 \\
\text { meses }\end{array}$ & $\begin{array}{c}11 \\
\text { meses }\end{array}$ & $\begin{array}{c}13 \\
\text { meses }\end{array}$ \\
\hline$\hat{\sigma}_{g p}^{2}$ & 0,07 & 0,64 & 0,68 & 190,56 & 307,56 & 488,96 & 27,81 & 35,86 & 26,48 & 26,34 \\
\hline$\hat{\sigma}_{a}^{2}$ & 0,26 & 2,56 & 2,71 & 762,22 & $1.230,24$ & $1.955,83$ & 111,22 & 143,44 & 105,90 & 105,38 \\
\hline$\hat{\sigma}_{e}^{2}$ & 0,12 & 1,00 & 1,31 & 20,99 & 15,01 & 264,78 & 0,88 & 3,73 & 5,62 & 1,93 \\
\hline$\hat{\sigma}_{a d}^{2}$ & 0,49 & 3,64 & 4,43 & 828,42 & $1.880,90$ & $2.525,14$ & 110,95 & 136,83 & 122,51 & 131,29 \\
\hline$\hat{\sigma}_{f}^{2}$ & 0,68 & 5,28 & 6,42 & $1.039,97$ & $2.203,46$ & $3.278,88$ & 139,64 & 176,42 & 154,59 & 159,57 \\
\hline$\hat{h}_{a}^{2}$ & 0,39 & 08 & 0,42 & 0,73 & 0,56 & 0,59 & 0,79 & 0,81 & 0,69 & 0,66 \\
\hline$\hat{h}_{m}^{2}:$ & 0,50 & 0,54 & 0,50 & 0,78 & 0,74 & 0,68 & 0,81 & 0,81 & 0,75 & 0,77 \\
\hline$\hat{h}_{a d}^{2}$ & 0,40 & 0,53 & 0,46 & 0,69 & 0,49 & 0,58 & 0,75 & 0,79 & 0,65 & 0,60 \\
\hline$\hat{r}_{a a}$ & 0,70 & 0,74 & 0,71 & 0,88 & 0,86 & 0,83 & 0,90 & 0,89 & 0,87 & 0,88 \\
\hline$C \hat{V}_{g i}(\%)$ & 16,25 & 31,85 & 28,63 & 11,42 & 23,36 & 25,63 & 47,20 & 43,51 & 35,79 & 29,70 \\
\hline$C \hat{V}_{g p}(\%)$ & 8,12 & 15,93 & 14,32 & 11,42 & 11,68 & 12,81 & 23,60 & 21,76 & 17,86 & 14,84 \\
\hline$C \hat{V}_{e}(\%)$ & 34,72 & 61,90 & 60,94 & 25,58 & 29,56 & 37,17 & 48,26 & 45,84 & 43,39 & 34,56 \\
\hline$\hat{b}$ & 0,23 & 0,26 & 0,24 & 0,45 & 0,39 & 0,34 & 0,49 & 0,48 & 0,41 & 0,43 \\
\hline $\begin{array}{c}\text { Média } \\
\text { fenotípica }\end{array}$ & 3,16 & 5,02 & 5,75 & 120,79 & 150,18 & 172,57 & 22,00 & 28,00 & 29,00 & 35,00 \\
\hline
\end{tabular}

$\hat{\sigma}_{g p}^{2}$ : variância genética entre progênies; $\hat{\sigma}_{a}^{2}$ : variância genética aditiva; $\hat{\sigma}_{e}^{2}$ : variância residual; $\hat{\sigma}_{a d}^{2}$ : variância dentro de progênies; $\hat{\sigma}_{f}^{2}$ : variância fenotípica; $\hat{h}_{a}^{2}$ : herdabilidade aditiva no sentido restrito; $\hat{h}_{m}^{2}$ : herdabilidade média de progênies; $\hat{h}_{a d}^{2}$ : herdabilidade aditiva entre progênies; $\hat{r}_{a a}$ : acurácia da seleção de progênies; $C \hat{V}_{g i}(\%)$ : coeficiente de variação genética aditiva individual; $C \hat{V}_{g p}(\%)$ : coeficiente de variação genética entre progênies; $C \hat{V}_{e}(\%)$ : coeficiente de variação experimental; $\hat{b}$ : coeficiente de variação relativo.

Os valores de herdabilidade média $\left(\hat{h}_{m}^{2}\right)$ foram considerados altos para todas os caracteres em todas as idades avaliadas (11,13 e 15 meses), que variaram entre 0,50 e 0,81 (Tabela 2). Isto indica que esses caracteres sofreram pouca influência do ambiente sendo controladas, principalmente, por componentes de variância genética, podendo ser utilizadas em programas de melhoramento para a seleção de indivíduos superiores.

Segundo Resende et al. (1995), a herdabilidade é considerada como baixa quando apresenta valores variando de 0,01 até 0,15, mediano de 0,15 até 0,50 e alto quando superiores a 0,50. Estimativas de coeficientes de herdabilidade altas indicam a forte possibilidade de obter ganhos genéticos com a seleção de progênies superiores fenotipicamente, considerando-se que traduzem o alto controle genético para os caracteres analisados (Henriques et al., 2017).

Ressalta-se que a altura é uma medida de fácil obtenção, sendo utilizada para estimar o padrão de qualidade das mudas em viveiros e considerada como um dos mais importantes parâmetros de estimativa do crescimento em campo. A ALT e o DC estão entre os parâmetros morfológicos mais importantes para estimativa de crescimento das mudas após plantio definitivo em campo (Gomes et al., 2002). Apesar de o NF apresentar a maior $\hat{h}_{m}^{2}(0,81)$, a seleção de mudas com base neste caractere torna-se pouco eficiente, devido à espécie ser considerada decídua (Lorenzi, 2009).

Os valores de herdabilidade individual $\left(\hat{h}_{a}^{2}\right)$ e herdabilidade entre progênies $\left(\hat{h}_{a d}^{2}\right)$ apresentaram valores próximo de $\hat{h}_{m}^{2}$, desta forma, visando a obtenção de maiores ganhos com a seleção genética, recomenda-se a seleção de indivíduos entre e dentro das progênies, 
bem como, a seleção massal, tendo em vista que a herdabilidade média apresentada foi considerada alta $\left(\hat{h}_{m}^{2}>0,5\right)$ para todos os caracteres.

Os caracteres NF e Bro apresentaram valores superiores para os coeficientes de herdabilidade $\left(\hat{h}_{a}^{2}, \hat{h}_{m}^{2}, \hat{h}_{a d}^{2}\right)$, em relação aos caracteres ALT e DC. Esses resultados devem-se ao fato de que essas variáveis (ALT e DC) geralmente são controladas por muitos genes e, consequentemente, sofrem forte influência do ambiente, apresentando valores menores de herdabilidade (Falconer, 1981).

A variação genética individual ( $C \hat{V}_{g i} \%$ ), variou de 11,42\% (ALT) a 47,20\% (NF). Pode-se dizer que estes valores são considerados altos, de acordo com o exposto por Sebbenn et al. (2008). Para esse autor, valores de $C \hat{V}_{g i} \%$ acima de $7 \%$ são considerados altos. Destaca-se que quanto maior o $C \hat{V}_{g i} \%$, maiores são as possibilidades de ganho genético ao longo do programa de melhoramento (Resende \& Duarte, 2007).

O coeficiente de variação genética entre progênies $\left(C \hat{V}_{g p} \%\right.$ ) apresentou valores variando entre $8,12 \%$ e 23,60\% para os caracteres DC e NF, respectivamente. Quando a espécie apresenta alto coeficiente de variação genética, é indicativo de que há potencial para melhoramento representando maiores ganhos genéticos na seleção recorrente (Zanata et al., 2010). De acordo com Biernaski et al. (2012), valores de coeficientes de variação genética dentro de progênies $\left(C \hat{V}_{g i} \%\right)$ são, geralmente, superiores aos coeficientes entre progênies ( $C \hat{V}_{g p} \%$ ) em teste de progênies envolvendo espécies arbóreas nativas, o que corrobora com os resultados da presente pesquisa. Ressalta-se que a principal vantagem do coeficiente de variação é possibilitar a quantificação e a ponderação da proporção da variação existente devida a fatores ambientais e genéticos, bem como à proporção que será repassada para a geração seguinte. Assim sendo, a obtenção deste parâmetro no presente estudo servirá de base para as tomadas de decisão quanto à condução de programas de melhoramento (Ferrão et al., 2008; Freitas et al., 2011) voltados para a C. xanthocarpa.

O coeficiente de variação relativa $(\hat{b})$ foi considerado de moderada magnitude variando de 0,23 a 0,49 para DC e NF, respectivamente. Isto pode ser justificado pelo alto coeficiente de variação experimental ( $C \hat{V}_{e} \%$ ) que variou de 25,58\%, para ALT aos 11 meses, a 61,90\%, para o DC aos 13 meses. Quanto maior o valor de $\hat{b}$, maior é o controle genético dos caracteres e menor é a influência dos fatores ambientais no fenótipo (Vencovsky \& Barriga, 1992).

A estimativa da acurácia seletiva $\left(\hat{r}_{a a}\right)$ é entendida como a relação entre o valor genético real e o valor estimado. Os valores obtidos para acurácia variaram entre 0,70 e 0,90 para os caracteres DC e NF, respectivamente, demonstrando elevado grau de confiabilidade dos resultados obtidos na avaliação genética das progênies (Resende, 2006). Os resultados com valores acima de 0,70 indicam que os valores estimados são válidos confrontados com os valores reais (Resende, 2002), o que permite apontar que todos os caracteres apresentaram valores altos de estimativas de acurácia.

Ressalta-se que os resultados desta pesquisa foram obtidos em avaliações precoces, devendo-se dar continuidade à coleta de dados para acompanhar a performance dos materiais ao longo do período de seu desenvolvimento em campo. O ensaio de campo foi implantado e será acompanhado durante os anos. Estamos interessados em avaliar a depressão por endogamia (Tambarussi et al., 2017) nas sementes das futuras gerações e no tamanho efetivo (Tambarussi et al., 2016).

\section{CONCLUSÃO}

Conclui-se que há variabilidade genética significativa entre e dentro de progênies, demonstrando o alto potencial desta população para melhoramento e conservação de $C$. xanthocarpa.

Os parâmetros genéticos, em especial os valores de coeficiente de herdabilidade, indicam que os caracteres estudados são pouco influenciados pelo ambiente, podendo-se realizar a seleção genética com base nos caracteres avaliados. 


\section{AGRADECIMENTOS}

Agradecemos ao Conselho Nacional de Desenvolvimento Científico e Tecnológico (CNPq) pela bolsa (PIBIC) da aluna Mariá Bach Kampa. Isabel Homczinski contou com o apoio da Coordenação de Aperfeiçoamento de Pessoal de Nível Superior (CAPES). Evandro Vagner Tambarussi é financiado pela bolsa produtividade (PQ-2) do CNPq.

\section{REFERÊNCIAS BIBLIOGRÁFICAS}

Aguiar, A. V., Sousa, V. A., \& Shimizu, J. Y. (2010). Seleção genética de progênies de Pinus greggii para formação de pomares de sementes. Pesquisa Florestal Brasileira, 30(62), 107-117. http://dx.doi.org/10.4336/2010.pfb.30.62.107.

Backes, P., \& Irgang, B. (2002). Árvores do Sul: guia de identificação \& interesse ecológico (326 p.). Porto Alegre: Instituto Souza Cruz.

Bardiviesso, D. M., Maruyama, W. I., Reis, L. L., Modesto, J. H., \& Rezende, W. E. (2011). Diferentes substratos e recipientes na produção de mudas de guabiroba (Campomanesia pubescens O. Berg.). Revista Científica Eletrônica de Agronomia, 18(1), 52-59.

Biavatti, M. W., Farias, C., Curtius, F., Brasil, L. M., Hort, S., Schuster, L., Leite, S. N., \& Prado, S. R. T. (2004). Preliminary studies on Campomanesia xanthocarpa (Berg.) and Cuphea carthagensis (Jacq.) J. F. Macbr. aqueous extract: weight control and biochemical parameters. Journal of Ethnopharmacology, 93(2-3), 385-389. http://dx.doi.org/10.1016/j.jep.2004.04.015. PMid:15234782.

Biernaski, F. A., Higa, A. R., \& Silva, L. D. (2012). Variabilidade genética para caracteres juvenis de progênies de Cedrela fissilis Vell.: subsídio para definição de zonas de coleta e uso de sementes. Revista Árvore, 36(1), 49-58. http://dx.doi.org/10.1590/S0100-67622012000100006.

Borém, A., \& Miranda, G. (2009). Melhoramento de plantas. Viçosa: Editorial UFV.

Carvalho, N. M., \& Nakagawa, J. (2000). Sementes: ciência, tecnologia e produção (4. ed., 588 p.). Jaboticabal: FUNEP.

Carvalho, P. E. R. (2006). Espécies arbóreas brasileiras (Vol. 2, pp. 261-268). Brasília: EMBRAPA-CNPFColombo.

Correia, D., Ribeiro, E. M., Lopes, L. S., Rossetti, A. G., \& Marco, C. A. (2005). Efeito de substratos na formação de porta-enxertos de Psidium guajava L. cv. Ogawa em tubetes. Revista Brasileira de Fruticultura, 27(1), 88-91. http://dx.doi.org/10.1590/S0100-29452005000100024.

Cruz, C. D. (2005). Princípios de genética quantitativa (394 p.). Viçosa: UFV.

Dalanhol, S. J., Nogueira, A. C., Gaiad, S., \& Kratz, D. (2017). Efeito de micorrizas e da fertilização no crescimento de mudas de Campomanesia xanthocarpa (Mart.) O. Berg. produzidas em diferentes substratos. Ciência Florestal, 27(3), 931-945. http://dx.doi.org/10.5902/1980509828665.

Falconer, D. S. (1981). Introduction to quantitative genetics (4. ed., 464 p). Edingburgh: Longman Group Limited.

Ferrão, R. G., Cruz, C. D., Ferreira, A., Cecon, P. R., Ferrão, M. A. G., Fonseca, A. F. A., Carneiro, P. C. S., \& Silva, M. F. (2008). Parâmetros genéticos em café Conilon. Pesquisa Agropecuária Brasileira, 43(1), 61 69. http://dx.doi.org/10.1590/S0100-204X2008000100009.

Figueiredo Filho, A., Nauiack, C. H. B., Roik, M., \& Gomes, G. S. (2013). Inventário das florestas nativas em pequenas propriedades rurais na bacia do Imbituvão, Centro-Sul do Paraná (115 p.). Irati, PR: UNICENTRO.

Freitas, J. B., Cândido, T. L. N., \& Silva, M. E. (2008). Geléia de guabiroba: avaliação da aceitabilidade e características físicas e químicas. Pesquisa Agropecuária Tropical, 38(2), 87-94.

Freitas, J. P. X., Oliveira, E. J., Cruz Neto, A. J., \& Santos, L. R. (2011). Avaliação de recursos genéticos de maracujazeiro-amarelo. Pesquisa Agropecuária Brasileira, 46(9), 1013-1020. http://dx.doi.org/10.1590/S0100-204X2011000900007.

Freitas, M. L. M., Sebbenn, A. M., Zanatto, A. C. S., \& Morais, E. (2007). Pomar de sementes por mudas a partir da seleção dentro em teste de progênies de Myracrodruon urundeuva Fr. All. Revista do Instituto Florestal, 19(2), 65-72.

Gogosz, A. M. (2008). Germinação e estrutura das plântulas de Campomanesia xanthocarpa O. Berg. (Myrtaceae) crescendo em solo contaminado com petróleo e solo biorremediado (Dissertação de mestrado). Universidade Federal do Paraná, Curitiba. 
Gogosz, A. M., Cosmo, N. L., Bona, C., \& Souza, L. A. (2010). Morfoanatomia da plântula de Campomanesia xanthocarpa O. Berg. (Myrtaceae). Acta Botanica Brasílica, 24(3), 616-623. http://dx.doi.org/10.1590/S0102-33062010000300003.

Gomes, J. M., Couto, L., Leite, H. G., Xavier, A., \& Garcia, S. L. R. (2002). Parâmetros morfológicos na avaliação da qualidade de mudas de Eucalyptus grandis. Revista Árvore, 26(6), 655-664. http://dx.doi.org/10.1590/S0100-67622002000600002.

Hartl, D. L. (2008). Princípios de genética de populações (3. ed., 217 p.). Ribeirão Preto: FUNPEC Editora.

Henriques, P. H., Moraes, C. B., Sebbenn, A. M., Tomazello-Filho, T., Moraes, M. L. T., \& Mori, E. S. (2017). Estimativa de parâmetros genéticos para caracteres silviculturais e densidade do lenho em teste de progênies de Eucalyptus urophylla. Scientia Forestalis, 45(113), 119-128. http://dx.doi.org/10.18671/scifor.v45n113.11.

Herzog, N. F. M., Malavasi, M. M., \& Malavasi, U. C. (2012). Morfometria dos frutos e germinação de sementes de Campomanesia xanthocarpa O. Berg. Semina: Ciências Agrárias, 33(4), 1359-1366. http://dx.doi.org/10.5433/1679-0359.2012v33n4p1359.

Homczinski, I. (2017). Distribuição espacial, dinâmica e biometria de Campomanesia xanthocarpa (Mart.) 0. Berg. em Florestal ombrófila mista (Dissertação de mestrado). Universidade Estadual do CentroOeste, Irati.

Homczinski, I., Figueiredo Filho, A., Retslaff, F. A. S., Dias, A. N., Figueiredo, A. P. M., Corrêa, A. J. M., \& Lerner, J. (2017). Biometric characterization of Campomanesia xanthocarpa (Mart.) O. Berg. in an Araucaria forest. Acta Biológica Catarinense, 4(2), 91-99. http://dx.doi.org/10.21726/abc.v4i2.445.

Kageyama, P. Y., \& Vencovsky, R. (1983). Variação genética em progênies de uma população de Eucalyptus grandis (Hill) Maiden. IPEF, 24, 9-26.

Klafke, J. Z., Silva, M. A., Panigas, T. F., Belli, K. C., Oliveira, M. F., Barichello, M. M., Rigo, F. K., Rossato, M. F., Santos, A. R. S., Pizzolatti, M. G., Ferreira, J., \& Viecilli, P. R. N. (2010). Effects of Campomanesia xanthocarpa on biochemical hematological and oxidative stress parameters in hypercholesteromic patients. Journal of Ethnopharmacology, 127(2), 299-305. http://dx.doi.org/10.1016/j.jep.2009.11.004. PMid:19914369.

Lorenzi, H. (2009). Árvores brasileiras: manual de identificação e cultivo de plantas arbóreas nativas do Brasil. Nova Odessa: Instituto Plantarum de Estudos da Flora.

Pinheiro, F. (2013). Plano de Manejo da Floresta Nacional de Irati (Vol. 1, p. 186). Brasília: ICMBIO.

Reflora. (2016). Campomanesia in Flora do Brasil 2020 em construção. Rio de Janeiro: Jardim Botânico do Rio de Janeiro. Recuperado em 18 de abril de 2018, de http://floradobrasil.jbrj.gov.br/reflora/ floradobrasil/FB10307

Resende, M. D. V. (2002). Genética biométrica e estatística no melhoramento de plantas perenes. Brasília: Embrapa informação Tecnológica (975 p.). Colombo: Embrapa Florestas.

Resende, M. D. V. (2006). O software Selegen-REML/BLUP. Campo Grande: Empresa Brasileira de Pesquisa Agropecuária.

Resende, M. D. V., \& Duarte, J. B. (2007). Precisão e controle de qualidade em experimentos de avaliação de cultivares. Pesquisa Agropecuária Tropical, 37(3), 182-194.

Resende, M. D. V., Araújo, A. J., Sampaio, P. T. B., \& Wiecheteck, M. S. S. (1995). Acurácia seletiva, intervalos de confiança e variância de ganhos genéticos associados a 22 métodos de seleção em Pinus caribaea var. hondurensis. Revista Floresta, 24, 35-45.

Santos, M. S., Carneiro, P. I. B., Wosiacki, G., Petkowicz, C. L. O., \& Carneiro, E. B. B. (2009). Caracterização físico-química, extração e análise de pectinas de frutos de Campomanesia xanthocarpa B. (Gabiroba). Ciências Agrárias, 30(1), 101-106. http://dx.doi.org/10.5433/16790359.2009v30n1p101.

Sarmento, M. B., Silva, A. C. S., \& Silva, C. S. (2012). Recursos genéticos de frutas nativas da família Myrtaceae no Sul do Brasil. Magistra, 24(4), 250-262.

Schaaf, L. B., Figueiredo Filho, A., Galvão, F., \& Sanquetta, C. R. (2009). Alteração na estrutura diamétrica de uma floresta ombrófila mista no período entre 1979 e 2000. Revista Árvore, 30(2), 283-295. http://dx.doi.org/10.1590/S0100-67622006000200016.

Sebbenn, A. M., Vilas Boas, O., \& Max, J. C. M. (2008). Altas herdabilidades e ganhos na seleção para caracteres de crescimento em teste de progênies de polinização aberta de Pinus elliottii Engelm var. elliottii aos 25 anos de idade em Assis-SP. Revista do Instituto Florestal, 20(2), 95-102.

Tambarussi, E. V., Boshier, D. H., Vencovsky, R., Freitas, M. L. M., Di-Dio, O. J., \& Sebbenn, A. M. (2016). Several small: how inbreeding affects conservation of Cariniana legalis Mart. Kuntze (Lecythidaceae) 
the Brazilian Atlantic Forest's largest tree. International Forestry Review, 18(4), 502-510. http://dx.doi.org/10.1505/146554816820127550.

Tambarussi, E. V., Boshier, D., Vencovsky, R., Freitas, M. L. M., \& Sebbenn, A. M. (2017). Inbreeding depression from selfing and mating between relatives in the Neotropical tree Cariniana legalis Mart. Kuntze. Conservation Genetics, 18(1), 225-234. http://dx.doi.org/10.1007/s10592-016-0896-4.

Vallilo, M. I., Moreno, P. R. H., Oliveira, E., Lamardo, L. C. A., \& Garbelotti, M. L. (2008). Composição química dos frutos de Campomanesia xanthocarpa (Mart.) O. Berg., Myrtaceae. Food Science and Technology (Campinas), 28(Suppl.), 231-237. http://dx.doi.org/10.1590/S0101-20612008000500035.

Venables, W. N., \& Ripley, B. D. (2002). Modern applied statistics with S (4th ed). USA: Springer. Recuperado em 18 de abril de 2018, de http: //www.stats.ox.ac.uk/pub/MASS4/

Vencovsky, R., \& Barriga, P. (1992). Genética biométrica no fitomelhoramento (496p.). Ribeirão Preto: Sociedade Brasileira de Genética.

Vinagre, A. S., Rönnau, A. D. S. R. O., Pereira, S. F., Silveira, L. U., Wiilland, E. F., \& Suyenaga, E. S. (2010). Anti-diabetic effects of Campomanesia xanthocarpa (Berg) leaf decoction. Brazilian Journal of Pharmaceutical Sciences, 46(2), 169-177. http://dx.doi.org/10.1590/S1984-82502010000200002.

Zanata, M., Freitas, M. L. M., Silva, M. T., Morais, E., Zanatto, A. C. S., \& Sebbenn, A. M. (2010). Parâmetros genéticos e ganhos na seleção em teste de progênies de polinização aberta de Eucalyptus pellita, Batatais-SP. Revista do Instituto Florestal, 22(2), 233-242.

Contribuição dos Autores: MBK: metodologia, investigação, escrita - primeira redação, escrita - revisão e edição; IH: curadoria de dados, metodologia, escrita - revisão e edição; RHR: metodologia, escrita - revisão e edição; AFF: visualização; FSBP: análise formal, visualização; EVT: conceituação, análise formal, supervisão, escrita - revisão e edição. 